broader criteria in evaluating the use of an investigation. These criteria should include the making of more confident diagnoses, and thus formulating management plans and prognostic expectations.

There is increasing public expectation that the investigation of dementia will include neuroradiological techniques. With the prospect of more overt rationing of limited resources, we urgently need to address the quality of health care provision particularly in terms of efficiency and effectiveness.

We are currently undertaking a large prospective study in the use of CT scans in the elderly, which we hope will address some of these issues.

DErTCH, J.T. (1983) Computerised tomographic scanning in cases of dementia. Western Journal of Medicine. 138, 835-837.

MARTIN, D.C., MULER, J., KAPOOR. W., KARPF, M. \& BOLLER, F. (1987) Clinical prediction rules for scanning in senile dementia. Archives of Internal Medicine, 147, 77-80.

WASSON, J.H., SOX, H.C., NEFF, R.K. \& GOLDMAN, L. (1985) Clinical prediction rules - applications and methodological standards. New England Journal of Medicine, 131, 793-797.

KAREN BLAGDEN, Queen's Medical Centre, Nottingham NG7 2UH; JANET BRUCE, Pastures Hospital, Mickleover, Derby DE3 5DQ; STEFFAN DAVIES, The Mullbrook Centre, Kings Mill Hospital, Mansfield NG17 4JL; and OLA JUNAID, St Francis Unit, City Hospital NHS Trust, Nottingham NG5 1PB

Sir: Blagden and colleagues raise some points regarding my article (Spear, Psychiatric Bulletin, 1993, 17, 536-537). I used a multidimensional definition of 'quality' (Maxwell, 1992). The dimensions of quality assessed were accessibility, efficiency and effectiveness.

Computerised tomography is useful in the diagnosis of dementia because it may detect other disorders such as subdural haematoma, brain tumour, normal pressure hydrocephalus and multi-infarct dementia (McKhann et al, 1984). Although I did not suggest that diagnosing potentially treatable structural lesions (PTL) is the only aim of computerised tomography (CT), by defining efficiency in terms of identification of PTL it was possible to compare the services with earlier research (Roberts \& Caird, 1990).

My study confirmed earlier research (Rilisoen \& Fossan, 1986) that the presence of focal neurological signs is the most useful predictor of PTLs. although a thorough medical history and further investigations are also important.

I welcome Blagden and colleagues' research which may offer further insights into the most appropriate use of CT scans in the elderly.

MAXWEL, R.J. (1992) Dimensions of quality revisited: from thought to action. Quality in Health Care, 1, 171-177.
McKhann, G., Drachman, D., Folstein, M., Katzman, R. et al (1984) Clinical diagnosis of Alzheimer's Disease. Neurology, 34, 939-946.

Risoen, H. \& Fossan, G.O. (1986) How shall we investigate dementia to exclude intracranial meningiomas as cause? Age and Ageing. 16, 29-34.

ROBERTS, M.A. \& CAIRD, F.I. (1990) The contribution of computerised tomography to the differential diagnosis of confusion in elderly patients. Age and Ageing, 19, 50-56.

JON SPEAR, York Clinic, Guy's Hospital, London SE1 9RT

\section{Care of patients discharged from hospital}

Sir: I have recently read the government's consultative paper about extending compulsory care to patients who have been discharged from hospital. While accepting that as professionals we have the luxury of being able to give the advice we believe to be correct without considering its public acceptability, a luxury not enjoyed by politicians, I fear from the tone of the paper that the proposed legislation is attempting to please everybody and deliberately vague.

Certainly neuroleptics have disadvantages and where practicable other methods of preventing relapse, and overwhelmingly we are talking of schizophrenia, are to be preferred. However, only two interventions reliably reduce relapse in schizophrenia, the administration of neuroleptics on a long-term basis and the manipulation of the environment with a reduction in high expressed emotion (HEE).

The reduction of HEE is clearly to be preferred but its delivery cannot be guaranteed and depends upon the ability and co-operation of many individuals, whereas administration of a depot neuroleptic is certain even if side effects have to be tolerated.

It is important that the College makes sure our advice to the government is unequivocal; if they wish to reduce unfortunate incidents involving discharged schizophrenic patients, the only legislative channel likely to achieve this is a power which will enable psychiatrists and multidisciplinary teams to insist that patients continue taking medication after discharge.

On the whole this is not difficult in practice and most patients will comply if the psychiatrist and the multidisciplinary team can tell them they must. Many are well versed in the technicalities of the Mental Health Act and know exactly when they are permitted to stop against medical advice.

I think the vast majority of the College, however, would agree that it is essential that the amendment to the Act says that patients in appropriate circumstances can be required to continue taking their medication after discharge from hospital and that this is written in such 